\title{
Tratamento de sementes de soja com inseticidas e um bioestimulante
}

\author{
Gustavo Spadotti Amaral Castro(1), Julio Cesar Bogiani(1), Matheus Gustavo da Silva( ${ }^{(2)}$, Eduardo Gazola(1) \\ e Ciro Antonio Rosolem ${ }^{(1)}$
}

(1)Universidade Estadual Paulista (Unesp), Faculdade de Ciências Agronômicas, Campus de Botucatu, Caixa Postal 237, CEP 18603-970 Botucatu, SP. E-mail: gsacastro@fca.unesp.br, jbogiani@fca.unesp.br, egazola@fca.unesp.br, rosolem@fca.unesp.br(2)Unesp, Faculdade de Engenharia de Ilha Solteira, Campus de Ilha Solteira, Caixa Postal 31, CEP 15385-000 Ilha Solteira, SP. E-mail: matheus@aluno.feis.unesp.br

Resumo - O objetivo deste trabalho foi avaliar o efeito do tratamento de sementes com inseticidas e um bioestimulante na germinação no crescimento da planta e raiz de soja. Foram realizados dois experimentos em delineamento de blocos ao acaso, em que as sementes foram tratadas com aldicarb, thiametoxan, imidacloprid e duas testemunhas: uma sem produto e uma com bioestimulante. Em laboratório, as unidades experimentais constituíram-se de rolos de papel toalha com sementes de soja, para avaliar o vigor, a germinação, as plantas anormais e mortas, o comprimento de radículas e de plântulas. Nos testes em casa de vegetação, as unidades experimentais constituíram-se de tubos de PVC, com volume de $16 \mathrm{dm}^{3}$, e foram avaliados: os teores de N, P e K; a matéria seca; o comprimento, a área e o raio médio radicular; a eficiência de absorção de N, P e K; e a taxa de crescimento radicular da soja. Os tratamentos de sementes de soja com os inseticidas e o bioestimulante levam à formação de raízes mais finas, o que caracteriza um efeito tônico. O produto aldicarb, na dose empregada, prejudica o vigor e a germinação das sementes de soja. O tratamento de sementes com inseticidas e bioestimulante não proporciona maior crescimento das raízes das plantas de soja.

Termos para indexação: Glycine max, crescimento de plantas, crescimento de raízes, efeito fitotônico, rizotron.

\section{Soybean seed treatment with insecticides and biostimulant}

\begin{abstract}
The objective of this work was to evaluate the effects of seed treatment with insecticides and biostimulant on soybean germination and plant and root growth. Two experiments were performed in complete randomized blocks, in which seeds were treated with aldicarb, thiamethoxan, imidacloprid and two checks: one without treatment and one treated with biostimulant. The experimental units at the laboratory were germination sheet rolls with soybean seeds. Plantlet vigor, germination, normal and abnormal plantlets, root and hypocotyl lengths were evaluated. For the greenhouse study PVC pots with $16 \mathrm{dm}^{-3}$ were used, and determinations were made for: N, P and K contents; dry matter yield; root length, surface and radius; N, P and K uptake efficiency; and root growth rate. Soybean treatments with insecticides and biostimulant led to thinner roots formation, which characterizes plant regulator-like effects. The product aldicarb used in dose applied affects the vigor and germination of seeds. Seed treatment with insecticides and biostimulant does not increase root and plant growth in soybean.
\end{abstract}

Index terms: Glycine max, plant growth, root growth, phytotonic effect, rhizotron.

\section{Introdução}

O uso de defensivos agrícolas no tratamento de sementes confere à planta condições de defesa, o que possibilita maior potencial para o desenvolvimento inicial da cultura. $\mathrm{O}$ controle de pragas e doenças que atacam a soja é realizado desde o início de seu ciclo com uso de defensivos no tratamento de sementes, sendo essa uma prática amplamente adotada e que se mostra eficiente (Martins et al., 1996; Raga et al., 2000; Siloto et al., 2000; Ceccon et al., 2004).
Os ingredientes ativos thiametoxan e imidacloprid, pertencentes ao grupo químico dos neonicotinóides, são substâncias sistêmicas de ação inseticida. Já o inseticida aldicarb pertence ao grupo químico do metilcarbamato de oxina, e também apresenta ação sistêmica.

Barbosa et al. (2002), ao estudar o efeito da aplicação dos inseticidas imidacloprid e o thiametoxan no tratamento de sementes de feijão, constataram que os ingredientes ativos proporcionaram melhoria nas características agronômicas da cultura, resultando em aumento de produtividade. 
Tavares et al. (2007) observaram efeito favorável com a aplicação do thiametoxan, com aumento da área foliar e radicular de plantas de soja tratadas com esse inseticida. O efeito do thiametoxan, na soja, é indireto, atuando na expressão dos genes responsáveis pela síntese e pela ativação de enzimas metabólicas, relacionadas ao crescimento da planta, alterando a produção de aminoácidos precursores de hormônios vegetais. Com a maior produção de hormônios, a planta apresenta maior vigor, germinação e desenvolvimento de raízes. Esse ingrediente ativo também melhora a nutrição mineral da soja, e estimula a expressão gênica das proteínas de membranas que aumentam o transporte iônico e a absorção de minerais.

Vem se tornando comum o tratamento de sementes com inseticidas que possuem atuação fisiológica nas plantas, com tendência de elas estabelecerem crescimento vigoroso e com melhor aproveitamento do seu potencial produtivo. Esse crescimento é conhecido como efeito fitotônico, que é caracterizado pelas vantagens positivas no crescimento e no desenvolvimento das plantas, proporcionadas pela aplicação de algum ingrediente ativo.

Da mesma forma, o emprego de bioestimulante como técnica agronômica para otimizar a produções em diversas culturas é cada vez mais comum (Dourado Neto et al., 2004). Os órgãos vegetais das plantas são alterados morfologicamente pela aplicação de bioestimulantes, de forma que o crescimento e o desenvolvimento deles são promovidos ou inibidos, o que influencia ou modifica os processos fisiológicos, e exerce controle da atividade meristemática (Weaver, 1972). Os bioestimulantes fazem parte do grupo denominado de hormônios vegetais, e pode-se citar: as auxinas, as citocininas, as giberilinas, os retardadores, os inibidores e o etileno.

A classificação do Stimulate foi feita por Castro et al. (1998), como sendo um bioestimulante que contém fitorreguladores. $\mathrm{Na}$ composição básica desse bioestimulante estão $0,005 \%$, de ácido indolbutírico (auxina), $0,009 \%$ de cinetina (citocinina) e $0,005 \%$ de ácido giberélico (giberelina). Como benefício da utilização dos bioestimulantes pode-se citar aumento do crescimento e do desenvolvimento vegetal, o que estimula a divisão, a diferenciação e o alongamento celular. Os mesmos autores ainda relatam aumento da absorção e da utilização de água e de nutrientes, sendo compatível com defensivos.
Vieira (2001) estudou o efeito de diferentes dosagens de Stimulate, nas culturas da soja, feijão e arroz, e obteve aumentos expressivos sobre a produtividade das plantas, quando o produto foi aplicado diretamente sobre as sementes. Quando foram avaliadas as concentrações de bioestimulante sobre as sementes, plântulas e plantas de soja, constatou-se que a concentração de $3,5 \mathrm{~mL}$ de Stimulate por $0,5 \mathrm{~kg}$ de sementes proporcionou a quantidade máxima de plântulas normais (51,9\% superior à testemunha). $\mathrm{O}$ máximo valor de massa de plântulas secas de soja foi obtido com a concentração de 4,1 mL de Stimulate, que superou em 55,3\% o controle. Com a concentração de $1,3 \mathrm{~mL}$, o crescimento radicular vertical alcançou o máximo valor $-26,5 \mathrm{~cm}-\mathrm{e}$ foi superior à testemunha. Quanto à produtividade, foram obtidos 157,4 grãos por planta de soja, com a concentração de $5 \mathrm{~mL}$ de Stimulate, que superaram em $24,3 \%$ a produtividade do controle. Dario et al. (2005) observaram que as aplicações de Stimulate no tratamento de sementes, via sulco de semeadura e aplicação foliar, aos 43 dias após a emergência da soja, não apresentaram resposta em relação à testemunha.

O objetivo deste trabalho foi avaliar o efeito do tratamento de sementes com inseticidas e um bioestimulante na germinação de sementes de soja e o efeito fitotônico no crescimento da planta e da raiz de soja.

\section{Material e Métodos}

Os experimentos foram conduzidos em casa de vegetação e no laboratório de sementes do Departamento de Produção Vegetal da Faculdade de Ciências Agronômicas da Unesp, em Botucatu, SP.

Nos dois experimentos, utilizou-se soja cultivar BRS 184 e cinco tratamentos de sementes constituídos por: T1, $125 \mathrm{~g}$ de thiametoxan (p.c. Cruiser) por $100 \mathrm{~kg}$ de sementes; T2, $500 \mathrm{~mL}$ de bioestimulante por $100 \mathrm{~kg}$ de sementes (p.c. Stimulate); T3, $150 \mathrm{~mL}$ de imidacloprid por $100 \mathrm{~kg}$ de sementes (p.c. Gaucho); T4, 9,5 $\mathrm{kg} \mathrm{ha}^{-1}$ de aldicarb (p.c. Temik); T5, testemunha, sem tratamento algum.

Por ocasião da aplicação dos tratamentos, em casa de vegetação e laboratório de sementes, as quantidades de cada produto foram diluídas em água destilada, formando uma calda homogênea, a fim de proporcionar o total recobrimento das sementes. Foi realizada a 
mistura das sementes com a calda em sacos de plástico de $2 \mathrm{~kg}$. O conjunto foi agitado vigorosamente durante dois min, visando a uniformizar os tratamentos sobre a massa de sementes. Os testes foram instalados após 30 min da aplicação do produto. A exceção foi o tratamento com aldicarb, que no experimento realizado em casa de vegetação, foi distribuído diretamente no sulco de semeadura.

O solo utilizado em casa de vegetação, classificado como Latossolo Vermelho distroférrico (Embrapa, 1999), de textura média $-630 \mathrm{~g} \mathrm{~kg}^{-1}$ de areia, $40 \mathrm{~g} \mathrm{~kg}^{-1}$ de silte e $330 \mathrm{~g} \mathrm{~kg}^{-1}$ de argila -, foi secado ao ar, e peneirado em malha de $2 \mathrm{~mm}$. A análise química revelou os seguintes valores: $\mathrm{pH} \mathrm{em} \mathrm{CaCl}_{2} 4,1 ; 1,0 \mathrm{mg} \mathrm{dm}^{-3} \mathrm{de}$ $\mathrm{P}_{\text {resina }} ; 18 \mathrm{~g} \mathrm{dm}^{-3}$ de matéria orgânica; $75 \mathrm{mmol}_{\mathrm{c}} \mathrm{dm}^{-3}$ de $\mathrm{H}+\mathrm{Al} ; 0,1 \mathrm{mmol}_{\mathrm{c}} \mathrm{dm}^{-3}$ de $\mathrm{K} ; 4 \mathrm{mmol}_{\mathrm{c}} \mathrm{dm}^{-3} \mathrm{de} \mathrm{Ca}$; $1 \mathrm{mmol}_{\mathrm{c}} \mathrm{dm}^{-3} \mathrm{de} \mathrm{Mg} ; 5,1 \mathrm{mmol}_{\mathrm{c}} \mathrm{dm}^{-3}$ de soma de bases (SB); 81,1 mmol $\mathrm{dm}^{-3}$ de CTC; e 6,3\% de saturação por bases (V). Foi aplicado calcário dolomítico (28\% de $\mathrm{CaO}, 20 \%$ de $\mathrm{MgO}$ e $95 \%$ de PRNT), para elevar a saturação por bases a $60 \%$. O solo foi umedecido à capacidade de campo e acondicionado sob lona de plástico por 20 dias. Em seguida, foi adubado com $190 \mathrm{mg} \mathrm{dm}^{-3}$ de $\mathrm{P}_{2} \mathrm{O}_{5}$ (superfosfato simples), $75 \mathrm{mg} \mathrm{dm}^{-3}$ de $\mathrm{K}_{2} \mathrm{O}$ (cloreto de potássio), $7 \mathrm{mg} \mathrm{L}^{-1}$ de $\mathrm{ZnSO}_{4}, 9 \mathrm{mg} \mathrm{L}^{-1}$ de ácido bórico, $1,3 \mathrm{mg} \mathrm{L}^{-1}$ de sulfato de cobre e $2,6 \mathrm{mg} \mathrm{L}^{-1}$ de sulfato de manganês.

As unidades experimentais constituíram-se de tubos de PVC, com diâmetro de $0,26 \mathrm{~m}$ e altura de $0,60 \mathrm{~m}$. Os tubos foram cortados ao meio no sentido longitudinal, formando uma face plana, na qual se instalou uma parede de vidro (rizotron), para propiciar o acompanhamento visual do crescimento radicular das culturas. Os tubos foram inclinados a $15^{\circ}$ para possibilitar o crescimento do sistema radicular paralelamente ao vidro. $\mathrm{O}$ volume de terra contido em cada unidade experimental foi de $16 \mathrm{dm}^{3}$. O teor de água foi monitorado diariamente e corrigido sempre que necessário, para que permanecesse próximo à capacidade de campo. Por ocasião da semeadura da soja, foi fixado um filme de plástico transparente na parede de vidro dos rizotrons, que foi utilizado para fazer as marcações e o acompanhamento do crescimento das raízes. Instalou-se uma placa de madeira laminada na janela dos rizotrons para evitar a incidência de luz no vidro e, com isso, a inibir o crescimento radicular.

Após três dias da semeadura da soja, iniciou-se a avaliação do crescimento do sistema radicular das raízes que cresceram paralelamente ao vidro, por meio de marcações no filme de plástico, com canetas coloridas. As avaliações repetiram-se em intervalos de 3 dias, até o 21ํ dia, num total de 7 avaliações. Após esse período, as plantas foram cortadas na altura do colo, para determinação da massa da matéria seca da parte aérea, e posterior determinação dos teores de N, P e K, segundo o método de Malavolta et al. (1997).

O solo foi retirado dos vasos e passado em peneiras de malha de $2 \mathrm{~mm}$, com auxílio de jatos de água, para separação das raízes de soja. As mesmas raízes foram secas em estufa de circulação forçada de ar a $60^{\circ} \mathrm{C}$, para determinação da massa da matéria seca. A eficiência de absorção de N, P e K foi calculada dividindo-se os respectivos teores de nutrientes pela massa da matéria seca das raízes.

Os filmes de plástico, com as anotações de crescimento radicular da soja, foram avaliados, seguindo o método proposto por Tennant (1975), e determinado o comprimento radicular $(\mathrm{L})$ e a área de superfície radicular (A). Seguindo o mesmo método, foi utilizada uma proveta graduada, na qual foram determinados os volumes de água, com raízes e sem raízes e, por diferença, foi obtido o volume radicular (V). Com esses dados, calculou-se o raio médio radicular $(\mathrm{R})$ pela equação: $\mathrm{R}=(\mathrm{V} / \pi \mathrm{L})^{0,5}$.

$\mathrm{O}$ delineamento experimental utilizado foi $\mathrm{o}$ de blocos ao acaso, com quatro repetições e cinco tratamentos. Os dados obtidos foram submetidos à análise de variância, e as médias dos tratamentos foram comparadas com a testemunha pelo teste t (DMS), a 5\% de probabilidade. Para o comprimento radicular e superfície radicular, foi realizada análise de regressão, considerando-se como fator quantitativo, as datas de avaliação. A partir da primeira derivada das equações de comprimento radicular da soja, obteve-se a taxa de crescimento relativo do comprimento radicular.

$\mathrm{O}$ experimento no laboratório de sementes, as unidades experimentais constituíram-se de rolos de papel com 50 e 10 sementes de soja, dependendo do teste realizado.

$\mathrm{O}$ teste de germinação foi realizado em papel toalha umedecido na proporção de 2,5 vezes a massa do substrato seco, com 50 sementes por repetição. Os rolos de papel, acondicionados em sacos de plástico, foram mantidos em germinador tipo BOD, a $25^{\circ} \mathrm{C}$. As contagens foram realizadas aos cinco e nove dias após a instalação do teste, seguindo os critérios 
estabelecidos em Brasil (1992). A primeira contagem de germinação constituiu-se na determinação, em percentagem, das plântulas normais aos cinco dias após a instalação do teste de germinação, e foi considerado como teste de vigor.

O comprimento das plântulas e radículas foram realizados com 10 sementes em cada repetição. As sementes foram distribuídas manualmente para germinar no sentido longitudinal das folhas do papel toalha, sobre a linha traçada no terço superior da folha, com os hilos voltados para a parte inferior do papel. Em seguida, foram confeccionados rolos, e colocados em sacos de plástico de coloração preta, a fim de manter constante a umidade no seu interior, e de eliminar o efeito da luminosidade. Os rolos foram distribuídos na posição vertical em germinador regulado a $25 \pm 1^{\circ} \mathrm{C}$, durante sete dias. A avaliação foi realizada efetuandose as medições das plântulas normais em centímetros (Nakagawa, 1999).

$\mathrm{O}$ delineamento experimental utilizado foi o de blocos ao acaso, com cinco repetições e cinco tratamentos. Os dados obtidos foram submetidos à análise de variância, e as médias dos tratamentos foram comparadas com a testemunha pelo teste $\mathrm{t}$ (DMS), a $5 \%$ de probabilidade.

\section{Resultados e Discussão}

Os valores obtidos para comprimento radicular da soja, em rizotron, se ajustaram a equações sigmoidais logísticas, para todos os tratamentos, com exceção do aldicarb, que se ajustou a uma função quadrática (Figura $1 \mathrm{~A}$ ). Verificou-se que, aos três dias após a semeadura (DAS), nos tratamentos com aldicarb e bioestimulante, o comprimento radicular das plantas de soja era menor que o da testemunha. Aos 6 e 9 DAS, somente as plantas que receberam o tratamento com bioestimulante apresentaram menor comprimento radicular, resultado contrário à sua finalidade de proporcionar efeito aditivo ao crescimento radicular. Leite et al. (2003) descrevem que a emergência das plantas de soja e o comprimento das raízes foram reduzidos com o tratamento de sementes com giberelina e citocinina, porém com o decorrer do experimento a diferença no crescimento radicular desapareceu.

Após essa avaliação, com exceção da realizada aos 15 DAS, em que a média do comprimento radicular das plantas de soja era inferior à obtida na testemunha, não foram observadas diferenças entre todos os tratamentos. Também foi observado que as médias obtidas nos tratamentos com imidacloprid e thiametoxan eram superiores às dos tratamentos com aldicarb e bioestimulante, o que persistiu até o fim do experimento. Basicamente, não se observaram efeitos positivos (fitotônicos e fisiológicos) nesses tratamentos que proporcionassem alguma alteração positiva no comprimento radicular da soja conduzida em rizotron, comparativamente à testemunha.

A taxa de crescimento radicular foi maior até os 6 DAS no tratamento testemunha. Comportamento semelhante foi observado para os tratamentos com thiametoxan
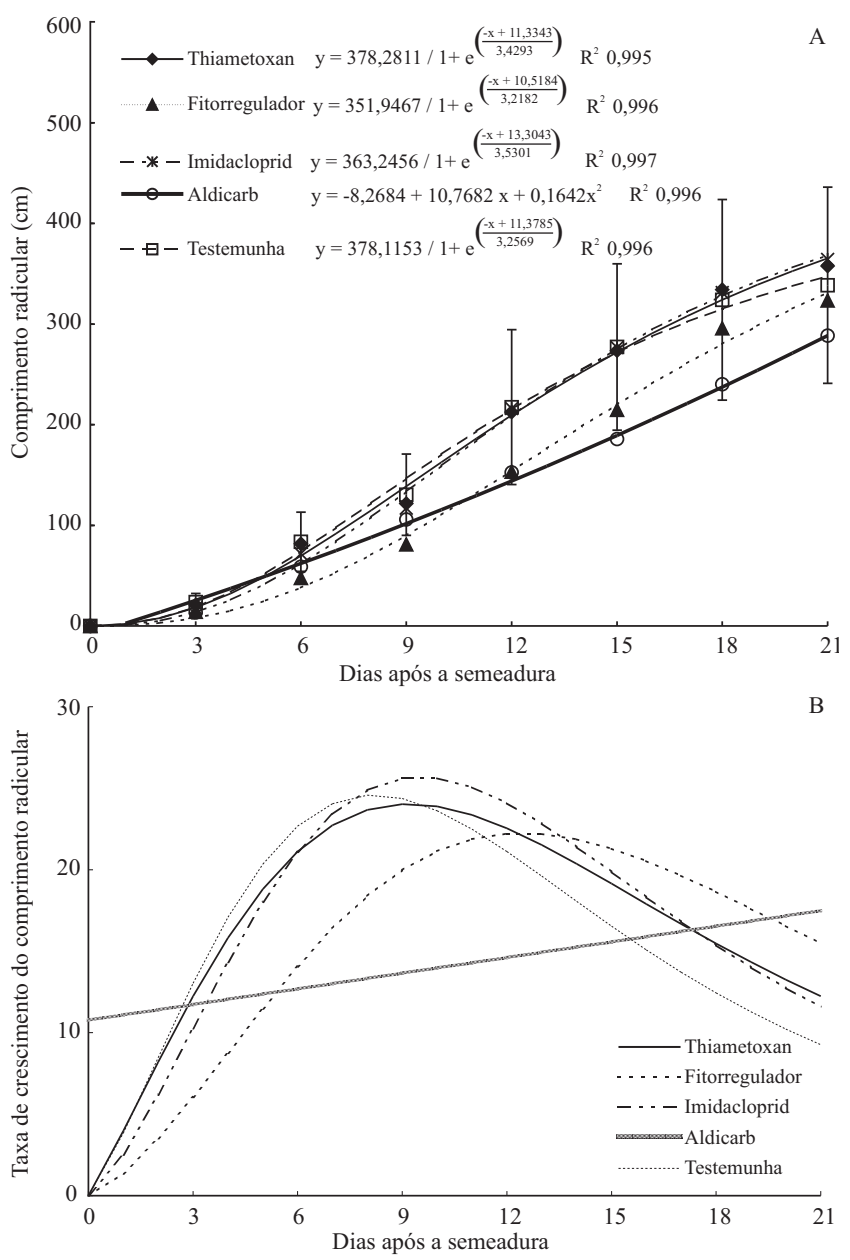

Figura 1. Comprimento radicular (A) com as respectivas equações e coeficientes de ajuste $\left(\mathrm{R}^{2}\right)$ e taxa de crescimento relativo do comprimento radicular (B), da soja cultivada em rizotron, em razão do tratamento com inseticidas e bioestimulante. Barras verticais indicam a diferença mínima significativa comparativamente à testemunha, pelo teste $t$, a $5 \%$ de probabilidade. 
e imidacloprid (Figura $1 \mathrm{~B}$ ). Aos 15 DAS, as plantas que receberam tratamento com bioestimulante tiveram recuperação, e superou as taxas observadas nos demais tratamentos. Naúltimaavaliação-21 DAS-, possivelmente, mais em razão da limitação de espaço do que propriamente o efeito dos tratamentos, a taxa de crescimento das raízes das plantas tratadas com thiametoxan, imidacloprid e testemunha tiveram redução. Para o tratamento com aldicarb, pôde-se observar que houve aumento lento na taxa de crescimento radicular, porém linear.

De modo geral, com exceção do tratamento com aldicarb, verificou-se que a soja apresenta maior taxa de crescimento em torno de 10 DAS, e estendeu-se até os 13 DAS, para o tratamento com bioestimulante.

Os resultados de superfície radicular da soja cultivada em rizotron, com exceção do tratamento com aldicarb, no qual os dados obtidos se ajustaram a uma função quadrática, foram semelhantes, se ajustando às equações sigmoidais logísticas (Figura 2). Foi observado que até os 3 DAS, as plantas de soja, com exceção daquelas tratadas com thiametoxan, apresentaram áreas radiculares inferiores à testemunha. Dos 6 aos 12 DAS, os valores de superfície radicular das plantas testemunha e das plantas tratadas com

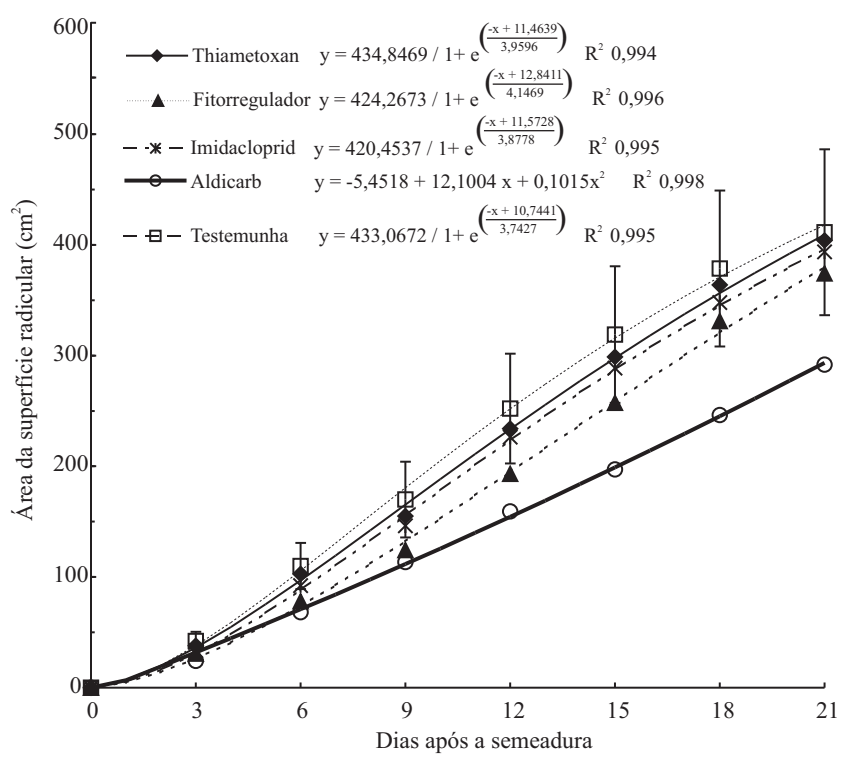

Figura 2. Área da superfície radicular da soja cultivada em rizotron e suas respectivas equações e coeficientes de ajuste $\left(\mathrm{R}^{2}\right)$, em razão do tratamento com inseticidas e bioestimulante. Barras verticais no gráfico indicam a diferença mínima significativa comparativamente à testemunha, pelo teste $\mathrm{t}$, a $5 \%$ de probabilidade. thiametoxan e imidacloprid se equivaleram; e a aplicação do tratamento com bioestimulante e aldicarb levaram à obtenção de plantas com valores de superfície radicular menor que a testemunha. Aos 12 DAS, as plantas tratadas com bioestimulante se equivaleram às tratadas com thiametoxan, imidacloprid e testemunha, contudo, as plantas tratadas com aldicarb permaneceram com valores de superfície radicular inferior às demais, e prevaleceu esse comportamento até o fim do experimento.

De modo geral, a utilização do tratamento com aldicarb proporcionou valores inferiores de superfície radicular, até o final das leituras, e isso se deu possivelmente à menor espessura das raízes, ou seja, as raízes das plantas de soja tratadas com aldicarb apresentaram, em números absolutos, os menores valores de raio médio radicular (Figura 3), o que pode ser considerado como um fator que venha proporcionar efeitos positivos ou tônicos, como melhor absorção de nutrientes com pouca mobilidade no solo, conforme relatado por Nielsen \& Barber (1978).

Com relação ao raio médio radicular, observou-se que nas plantas testemunha, a média foi significativamente superior aos outros tratamentos (Figura 3). As plantas tratadas com aldicarb também mostraram raio médio radicular significativamente menor que o das plantas tratadas com thiametoxan.

Os valores de massa de matéria seca da raiz e da parte aérea comportaram-se de acordo com os resultados anteriores, pois a menor superfície do sistema radicular das plantas de soja, proporcionado pelo tratamento com aldicarb, resultou em menor massa da matéria seca da raiz (Tabela 1). No entanto, para matéria seca de raiz, o tratamento com aldicarb não diferiu do tratamento

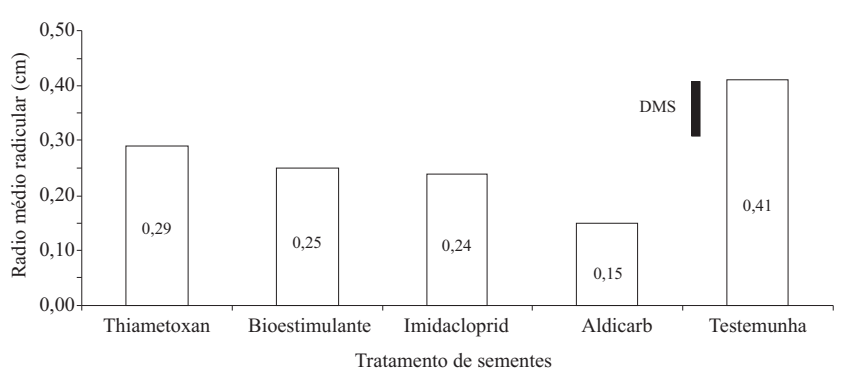

Figura 3. Raio médio radicular da soja cultivada em rizotron, em razão dos tratamentos de sementes com inseticidas e bioestimulante. DMS: diferença mínima significativa, comparativamente à testemunha, pelo teste $\mathrm{t}$, a $5 \%$ de probabilidade. 
com bioestimulante. Tavares et al. (2007) observaram significância entre doses de thiametoxan, aplicadas às sementes de soja, e estimaram que o máximo de matéria seca das raízes foi obtida na dose de $44,5 \mathrm{~g}$ de i.a.

Os valores nutricionais da soja, observados para $\mathrm{Ne}$ $\mathrm{K}$ não foram alterados (Tabela 2). Para o $\mathrm{P}$, as plantas tratadas com aldicarb apresentaram maiores valores, obtidos pela menor produção de massa de matéria seca desse tratamento. Outra hipótese é de que, como Nielsen \& Barber (1978) relataram, com a melhoria nos parâmetros da cinética de absorção, os sistemas radiculares mais finos têm geometria mais favorável à absorção de nutrientes pouco móveis no solo, como é o P. E, com isso, plantas tratadas com aldicarb, por possuírem raízes mais finas, puderam se beneficiar com a absorção desse nutriente.

Para os valores de eficiência na absorção de $\mathrm{N}$ e K, não foram constatadas alterações pela aplicação dos tratamentos (Tabela 2). Conforme ocorrido com o teor foliar de $\mathrm{P}$, a eficiência de absorção desse nutriente foi superior nas plantas tratadas com aldicarb, em relação às demais, em razão do menor raio médio radicular e da menor produção de massa de matéria seca, o que favoreceu a relação entre o teor acumulado de $\mathrm{P}$ e o comprimento radicular da soja.

O tratamento das sementes é considerado o método mais eficiente do uso de inseticidas no controle de pragas incidentes, durante o desenvolvimento inicial das culturas. Além disso, resultados de pesquisas têm evidenciado que alguns produtos, quando aplicados sozinhos ou em combinação com fungicidas, podem, em determinadas situações, ocasionar redução na germinação das sementes e na sobrevivência das plântulas, devido ao efeito de fitotoxicidade (Oliveira \& Cruz, 1986).

Neste trabalho, foi observado maior vigor em sementes dos tratamentos testemunha e imidacloprid, que diferiram dos demais, com exceção do tratamento com thiametoxan (Tabela 3). Para a germinação, todos os tratamentos apresentaram valores superiores a $80 \%$, valor mínimo referenciado por Brasil (2005), o que caracteriza a ausência de efeitos danosos sobre esse parâmetro. $\mathrm{O}$ maior valor de germinação observado foi na testemunha, porém, diferiu significativamente dos tratamentos com thiametoxan e aldicarb, mostrando, portanto, que o ingrediente ativo contido no produto químico foi prejudicial ao desenvolvimento das plântulas de soja, conforme relatado por Oliveira \& Cruz (1986). Em contrapartida, Tavares et al. (2007) não observaram nenhuma diferença de germinação e de vigor quando utilizaram diferentes doses de thiametoxan no tratamento com sementes de soja. Barros et al. (2001) também não observaram redução da germinação em relação à testemunha quando utilizaram thiametoxan na cultura do feijão.

Observa-se que onde não houve tratamento de sementes, o número de plantas anormais foi inferior, o queindica que, pelo menos em laboratório, otratamento de sementes com inseticidas ou hormônios interferiu negativamente no desenvolvimento inicial das plantas e proporcionou alterações fisiológicas. Para plantas mortas, houve diferença entre os tratamentos com o thiametoxan, que apresentou a maior percentagem, evidenciando que esse tratamento pode causar uma diminuição no estande inicial da cultura.

Para o comprimento de plântulas, em todas as avaliações, os valores obtidos no tratamento com thiametoxan foram os maiores, no entanto, foi significativo apenas no tratamento com aldicarb. O mesmo aconteceu para o comprimento de radículas (Tabela 4). Tavares et al. (2007) não encontraram

Tabela 1. Produção de matéria seca radicular (MSR), matéria seca da parte aérea (MSPA) e teor foliar de nitrogênio (N), fósforo $(\mathrm{P})$ e potássio $(\mathrm{K})$, no tecido vegetal da soja cultivada em rizotron, nos diferentes tratamentos com inseticidas e bioestimulante.

\begin{tabular}{|c|c|c|c|c|c|}
\hline \multirow[t]{2}{*}{ Tratamento } & MSR & MSPA & $\mathrm{N}$ & $\mathrm{P}$ & $\mathrm{K}$ \\
\hline & ------------- & ------------ & ------------ & $-\left(\mathrm{g} \mathrm{kg}^{-1}\right)$ & ------- \\
\hline Thiametoxan & 0,75 & 1,15 & 49,95 & 0,46 & 4,5 \\
\hline Bioestimulante & 0,73 & 1,20 & 46,76 & 0,63 & 5,0 \\
\hline Imidacloprid & 0,80 & 1,30 & 47,74 & 0,88 & 6,7 \\
\hline Aldicarb & 0,53 & 0,94 & 49,14 & 1,38 & 5,8 \\
\hline Testemunha & 0,93 & 1,26 & 50,19 & 0,57 & 5,6 \\
\hline$\overline{\mathrm{CV}}(\%)$ & 19,4 & 9,3 & 5,0 & 24,3 & 34,6 \\
\hline DMS & $0,22 *$ & $0,17 *$ & $3,7^{\mathrm{ns}}$ & $0,30 *$ & $2,9^{\mathrm{ns}}$ \\
\hline
\end{tabular}

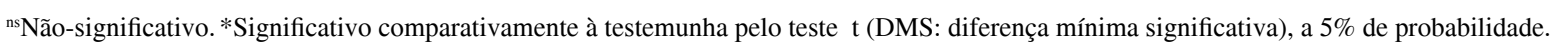


Tabela 2. Eficiência de absorção de nitrogênio $(\mathrm{N})$, fósforo (P) e potássio $(\mathrm{K})$, no tecido vegetal da soja cultivada em rizotron, nos diferentes tratamentos com inseticidas e bioestimulante.

\begin{tabular}{lccc}
\hline Tratamento & $\mathrm{N}$ & $\mathrm{P}$ & $\mathrm{K}$ \\
\hline Thiametoxan & 112,3 & 1,0 & 10,2 \\
Bioestimulante & 121,3 & 1,6 & 12,8 \\
Imidacloprid & 119,2 & 2,2 & 16,7 \\
Aldicarb & 112,2 & 3,2 & 13,3 \\
Testemunha & 130,8 & 1,5 & 14,7 \\
\hline CV $(\%)$ & 13,2 & 22,5 & 32,7 \\
DMS & $24,6^{\text {ns }}$ & $0,7^{*}$ & $6,9^{\text {ns }}$ \\
\hline
\end{tabular}

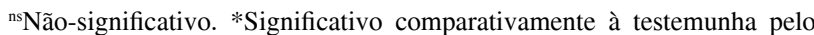
teste t (DMS: diferença mínima significativa), a 5\% de probabilidade.
Tabela 3. Percentagens de vigor, germinação de sementes, plântulas anormais e mortas de soja, em laboratório, nos diferentes tratamentos com inseticidas e bioestimulante.

\begin{tabular}{lcccc}
\hline Tratamento & Vigor & Germinação & Anormais & Mortas \\
\hline Thiametoxan & 77 & 86 & 10 & 5 \\
Bioestimulante & 76 & 90 & 9 & 1 \\
Imidacloprid & 84 & 91 & 7 & 3 \\
Aldicarb & 64 & 81 & 7 & 3 \\
Testemunha & 85 & 96 & 4 & 1 \\
\hline CV $(\%)$ & 6,4 & 88,5 & 35,6 & 66,8 \\
DMS & $8^{*}$ & $6^{*}$ & $5^{*}$ & $3^{*}$ \\
\hline
\end{tabular}

*Significativo comparativamente à testemunha pelo teste t (DMS: diferença mínima significativa), a 5\% de probabilidade.

Tabela 4. Comprimento radicular $(\mathrm{cm})$ e de parte aérea $(\mathrm{cm})$ da soja, em laboratório, em razão do número de dias após a aplicação dos diferentes tratamentos com inseticidas e bioestimulante.

\begin{tabular}{|c|c|c|c|c|c|c|}
\hline \multirow[t]{2}{*}{ Tratamento } & \multicolumn{3}{|c|}{ Comprimento radicular } & \multicolumn{3}{|c|}{ Comprimento de parte aérea } \\
\hline & 2 dias & 4 dias & 8 dias & 2 dias & 4 dias & 8 dias \\
\hline Thiametoxan & 3,7 & 6,1 & 15,0 & - & 4,7 & 14,2 \\
\hline Bioestimulante & 2,8 & 5,1 & 14,1 & - & 4,2 & 12,3 \\
\hline Imidacloprid & 2,7 & 4,8 & 10,6 & - & 3,5 & 11,9 \\
\hline Aldicarb & 2,5 & 3,3 & 6,8 & - & 2,3 & 8,4 \\
\hline Testemunha & 2,5 & 4,7 & 13,8 & - & 3,4 & 12,6 \\
\hline $\mathrm{CV}(\%)$ & 25,3 & 25 & 23,4 & - & 25,0 & 21,3 \\
\hline DMS & $1,1^{*}$ & $1,9^{*}$ & $4,4^{*}$ & - & $1,4^{*}$ & $3,9 *$ \\
\hline
\end{tabular}

*Significativo comparativamente à testemunha pelo teste t (DMS: diferença mínima significativa), a 5\% de probabilidade.

diferença no desenvolvimento do hipocótilo e radícula de plântulas de soja, submetida a cinco doses de thiametoxan, no tratamento de sementes de soja.

\section{Conclusões}

1. O tratamento de sementes de soja com os inseticidas e o bioestimulante levam à formação de raízes de soja mais finas, o que caracteriza um efeito tônico.

2. O tratamento de sementes de soja com aldicarb prejudica o vigor e a germinação.

3. O tratamento de sementes de soja com inseticidas e bioestimulante não proporciona maior crescimento das raízes.

\section{Referências}

BARBOSA, F.R.; SIQUEIRA, K.M.M. de; SOUZA, E.A. de; MOREIRA, W.A.; HAJI, F.N.P.; ALENCAR, J.A. de. Efeito do controle químico da mosca-branca na incidência do vírusdo-mosaico-dourado e na produtividade do feijoeiro. Pesquisa Agropecuária Brasileira, v.37, p.879-883, 2002.
BARROS, R.G.; YOKOYAMA, M.; COSTA, J.L. da S. Compatibilidade do inseticida thiamethoxan com fungicidas utilizados no tratamento de sementes de feijoeiro. Pesquisa Agropecuária Tropical, v.31, 153-157, 2001.

BRASIL. Ministério de Agricultura, Pecuária e Abastecimento. Instrução normativa no 25 , de 16 de dezembro de 2005. Padrões para produção e comercialização de sementes de soja. Anexo IX. Diário Oficial [da] República Federativa do Brasil, Poder Executivo, Brasília, DF, 20 dez. 2005. Seção 1, p.18.

BRASIL. Ministério da Agricultura e Reforma Agrária. Regras para análise de sementes. Brasília: SNDA, 1992. 365p.

CASTRO, P.R.C.; PACHECO, A.C.; MEDINA, C.L. Efeitos de Stimulate e de micro-citros no desenvolvimento vegetativo e na produtividade da laranjeira 'Pêra' (Citrus sinensis L. Osbeck). Scientia Agricola, v.55, p.338-341, 1998.

CECCON, G.; RAGA, A.; DUARTE, A.P.; SILOTO, R.C. Efeito de inseticidas na semeadura sobre pragas iniciais e produtividade de milho safrinha em plantio direto. Bragantia, v.63, p.227-237, 2004.

DARIO, G.J.A.; MARTIN, T.N.; DOURADO NETO, D.; MANFRON, P.A.; BONNECARRÈRE, R.A.G.; CRESPO, P.E.N. Influência do uso de fitorregulador no crescimento da soja. Revista da Faculdade de Zootecnia, Veterinária e Agronomia, v.12, p.63-70, 2005. 
DOURADO NETO, D.; DARIO, G.J.A.; VIEIRA JÚNIOR, P.A.; MANFRON, P.A.; MARTIN, T.N.; BONNECARRÉRE, R.A.G.; CRESPO, P.E.N. Aplicação e influência do fitorregulador no crescimento das plantas de milho. Revista da Faculdade de Zootecnia, Veterinária e Agronomia, v.11, p.93-102, 2004.

EMBRAPA. Sistema brasileiro de classificação de solos. Brasília: Embrapa Produção de Informação; Rio de Janeiro: Embrapa Solos, 1999. 412p.

LEITE, V.M.; ROSOLEM, C.A.; RODRIGUES, J.D. Gibberellin and cytokinin effects on soybean growth. Scientia Agricola, v.60, p.537-541, 2003.

MALAVOLTA, E.; VITTI, G.C.; OLIVEIRA, S.A. de. Avaliação do estado nutricional das plantas: princípios e aplicações. 2.ed. Piracicaba: Potafos, 1997. 319p.

MARTINS, J.F. da S.; BOTTON, M.; CARBONARI, J.J. Efeito de inseticidas no tratamento de sementes e na água de irrigação no controle de Oryzophagus oryzae (Costa Lima), em arroz irrigado. Revista Brasileira de Agrociência, v.2, p.27-32, 1996.

NAKAGAWA, J. Testes de vigor baseados no desempenho das plântulas. In: KRZYZANOWSKI, F.C.; VIEIRA, R.D.; FRANÇA NETO, J.B. (Ed.). Vigor de sementes: conceitos e testes. Londrina: Abrates, 1999. p.2-21.

NIELSEN, M.E.; BARBER, S.A. Differences among genotypes of corn in the kinetics of P uptake. Agronomy Journal, v.70, p.695-698, 1978.
OLIVEIRA, L.J.; CRUZ, I. Efeito de diferentes inseticidas e dosagens na germinação de sementes de milho (Zea mays L.). Pesquisa Agropecuária Brasileira, v.21, p.578-585, 1986.

RAGA, A.; SILOTO, R.C.; SATO, M.E. Efeito de inseticidas sobre o percevejo castanho Scaptocoris castanea (Hem.: Cydnidae) na cultura algodoeira. Arquivos do Instituto Biológico, v.67, p.93-97, 2000 .

SILOTO, R.C.; SATO, M.E.; RAGA, A. Efeito de inseticidas sobre percevejo castanho Scaptocoris castanea (Perty) (Hem.: Cydnidae) em cultura de milho-safrinha. Revista de Agricultura, v.75, p.21-27, 2000.

TAVARES, S.; CASTRO, P.R.C.; RIBEIRO, R.V.; ARAMAKI, P.H. Avaliação dos efeitos fisiológicos de thiametoxan no tratamento de sementes de soja. Revista de Agricultura, v.82, p.47-54, 2007.

TENNANT, D. A test of a modified line intersect method of estimating root length. Journal of Ecology, v.63, p.995-1001, 1975.

VIEIRA,E.L.Açãodebioestimulantenagerminação desementes, vigor de plântulas, crescimento radicular e produtividade de soja (Glycine max (L.) Merril), feijoeiro (Phaseolus vulgaris $\mathbf{L}$.) e o arroz (Oriza sativa L.). 2001. 122p. Tese (Doutorado) - Escola Superior de Agricultura Luiz de Queiroz, Piracicaba.

WEAVER, R.J. Plant growth substances in agriculture. San Francisco: W.H. Freeman, 1972. 594p.

Recebido em 31 de outubro de 2007 e aprovado em 3 de setembro de 2008 